\title{
Perubahan Garis Pantai Pada Morfologi Gisik Kantung di Pantai Baron, Kabupaten Gunungkidul Daerah Istimewa Yogyakarta
}

\author{
Anggardha Ayu Pratiwi ${ }^{1 *}$, Heryoso Setiyono ${ }^{1}$, Agus Anugroho Dwi Suryoputro ${ }^{1}$, Jarot \\ Marwoto $^{1}$, Alfi Satriadi ${ }^{1}$ \\ ${ }^{I}$ Departemen Oseanografi, Fakultas Perikanan dan Ilmu Kelautan, Universitas Diponegoro, Jl. Prof. Sudarto. \\ SH Tembalang Tlp / Fax (024)7474698 Semarang 50275 \\ Email:*anggardhapratiwi31@gmail.com
}

\begin{abstract}
Abstrak
Pantai Baron merupakan salah satu pantai yang berbatasan langsung dengan Samudera Hindia, yang terletak di Desa Kemadang, Kecamatan Tanjungsari, Kabupaten Gunung Kidul Daerah Istimewa Yogyakarta. Pantai Baron terletak di antara dua tebing terjal (cliff) sehingga terbentuk morfologi gisik kantung (pocket beach) yang memiliki hamparan pasir yang terbentuk dari hasil sedimentasi. Permasalahan utama di lokasi penelitian yaitu terjadi perubahan garis pantai yang cukup dinamis. Perubahan garis pantai yang terjadi di sepanjang pantai Baron dapat berupa proses abrasi dan akresi. Tujuan dari penelitian ini untuk mengetahui luasan perubahan garis pantai yang terjadi. Metode yang digunakan dalam penelitian ini adalah metode kuantitatif yang bersifat deskriptif. Hasil dari penelitian ini adalah perubahan garis pantai yang terjadi di pantai Baron selama kurun waktu 2010-2018. Total luasan abrasi yang terjadi adalah 2,75 ha dan total luasan akresi 1,07 .
\end{abstract}

Kata Kunci: Pantai Braron, Garis Pantai, Abrasi, Akresi

\section{Abstract}

Baron Beach is one of the beaches directly adjacent to the Indian Ocean, located in Kemadang Village, Tanjungsari Sub-District, Gunung Kidul Regency Special Region of Yogyakarta. Baron Beach is located between cliffs, with pocket beaches that have a stretch of sand formed from the destruction of organic matter millions of years ago. The main problem is the problem of coastline changes that occur over an annual period, having a fairly dynamic coastline change. The changes in coastline that occur along baron beach can be a process of abrasion and accretion. The purpose of this study is to find out the extent of the changes in the coastline that occur. The method used in this study is a descriptive quantitative method. Quantitative method due to research data in the form of numbers and analysis using statistics, is descriptive because this method makes an overview of an event and situation researched in a limited time with a specific region and produces an overview of the situation. The result of this study is that the changes in the coastline that occurred on baron beaches are quite dynamic in the period 20102018. The total area of abrasion occurred was 2.75 ha and the total accretion area was 1.07 .

Keywords: Baron beach, Shoreline, Abrasion, Accresion

\section{PENDAHULUAN}

Pantai Baron terletak di Desa Kemadang, Kecamatan Tanjungsari, Kabupaten Gunung Kidul. Pantai Baron ini dikelilingi bukit-bukit kapur yang diatasnya terdapat jalan setapak dengan gardu pandang untuk menikmati keindahan laut dari ketinggian (Anisa dan Adjie, 2018). Pantai Baron mempunyai bentuk menjorok ke darat (teluk) dan memiliki muara sungai. Keberadaan muara sungai memberikan pengaruh yang cukup kuat pada karakteristik sedimen pada pantai dan aliran sungai menuju samudera. Pengaruh gelombang dan tidak terdapatnya penghalang (barrier) membuat Pantai Baron sangat mudah tererosi walaupun dengan tenaga yang jauh lebih kecil sebagai akibat lereng gisik pantai yang landai.

Permasalahan yang utama di pantai Baron yaitu terjadi perubahan garis pantai dalam kurun waktu tahunan, memiliki perubahan garis pantai yang cukup dinamis, walaupun jika di lihat pantai Baron 
merupakan pantai yang tidak cukup luas, dengan panjang garis pantai $60 \mathrm{~m}$, karena karakteristik pantainya yang menyerupai teluk. Pesisir pantai Baron dicirikan dengan bentuk pantai yang memiliki material endapan marin. Endapan marin merupakan batuan endapan yang terjadi akibat adanya proses sedimentasi oleh air laut. Tipe-tipe ini terbentuk pada teluk-teluk yang kemudian dikenal juga dengan sebutan gisik kantung (pocket beach) (Muhamad et all, 2013).

Menurut Balouin (2014) pocket beach atau gisik kantung merupakan pantai kecil yang terbentuk diantara tanjung di teluk pantai berbatu. Pesisir ini terdiri dari campuran batu-batu besar, krikil, pasir dan lumpur. Perubahan garis pantai yang terjadi tidak lepas dari pengaruh faktor alam dan faktor manusia. Faktor alam merupakan peristiwa alam yang dapat mengganggu keseimbangan lingkungan.

Faktor alam yang berpengaruh pada perubahan garis pantai ini contohnya gelombang, karena gelombang datang sepanjang garis pantai dapat mengakibatkan terbawanya material sedimen tiap satuan waktu yang terjadi secara terus menerus, angin karena angin menjadi salah satu faktor utama yang menyebabkan terjadi nya gelombang. Faktor kelerengan karena kelerengan akan mempengaruhi energi gelombang yang datang, misalkan tipe kelerengan landai maka energi gelombangnya kecil, sedangkan pantai dengan tipe kelerengan curam memiliki energi gelombang yang kuat sehingga menyebabkan perpindahan sedimen dasar.

Kondisi pasang surut di lokasi juga mempengaruhi garis pantai, karena pada saat terjadinya pasang maka garis pantai akan semakin mundur ke darat, sedangkan pada kondisi surut garis pantai akan maju ke arah laut. Garis pantai akan cepat berubah di wilayah pesisir dengan lereng pantai yang landai seperti di daerah yang sering terjadi proses pasang surut/macrotidal (Aguilar, et al., 2010).

Faktor yang terakhir adalah faktor ukuran butiran sedimen karena ukuran butiran akan mempengaruhi proses transport sedimen dipantai, yang akan memberikan dampak pada perubahan kemiringan pantai, bahkan dapat mengganggu proses keseimbangan pantai (Degen et al, 2018). Faktor manusia juga dapat merusak suatu ekosistem atau lingkungan contoh adalah penambangan pasir.

Perubahan terhadap garis pantai merupakan satu proses tanpa henti (terus menerus) melalui berbagai proses baik pengikisan (abrasi) ataupun penambahan (akresi). Berdasarkan kondisi yang terjadi pada kawasan pesisir Pantai Baron, maka diperlukan kajian atau penelitisn terhadap perubahan garis pantai pada wilayah tersebut guna memberikan informasi secara spasial dan akurat. Penelitian ini menggunakan data citra satelit dari Google Earth tahun 2010,2013, 2016 dan 2018 guna membandingkan perubahan yang terjadi.

\section{METODE PENELITIAN}

\section{Materi Penelitian}

Materi atau data yang digunakan dalam penelitian ini terbagi menjadi dua kategori yaitu data primer dan data sekunder. Data primer merupakan data yang digunakan adalah data hasil pengukuran yang diperoleh di lapangan, sedangkan data sekunder merupakan data yang digunakan sebagai data pendukung dari data utama dalam penelitian dari situs resmi maupun instansi terkait untuk menunjang data penelitian. Data primer yang digunakan dalam penelitian ini adalah:

1. Data kelerengan pantai yang diperoleh dari observasi lapangan yang diambil di lokasi penelitian

2. Data ukuran butir sedimen yang diperoleh dari obsevasi di lapangan

Data Sekunder yang digunakan yaitu:

1. Citra Satelit Google Earth, dengan tanggal perekaman 3 Juli 2010, 9 Oktober 2013, 8 September 2016 dan 5 Maret 2018

2. Data Pasang surut tahun 2018 yang diterbitkan oleh Badan Informasi Geospasial dilaman tides.big.go.id/pasut/

3. Data angin tahun 2018 yang diterbitkan oleh ECMWF (European Center for Medium-Range Weather Forecasts) dilaman www.ecmwf.int/

4. Peta rupa bumi Indonesia yang diterbitkan oleh Badan Informasi Geospasial (BIG). 


\section{Metode}

Metode yang digunakan dalam penelitian ini adalah metode kuantitatif yang bersifat deskriptif. Metode kuantitatif dikarenakan data penelitian yang berupa angka dan analisis menggunakan statistik. Metode deskriptif merupakan metode yang membuat sebuah gambaran dari suatu kejadian maupun situasi yang diteliti dalam waktu terbatas dengan wilayah tertentu dan menghasilkan gambaran situasi serta kondisi lokal (Sugiyono, 2009). Metode deskriptif dalam penelitian ini adalah untuk memperoleh suatu gambaran mengenai perubahan garis pantai dilokasi penelitian.

Penelitian ini menggunakan pendekatan penginderaan jauh yang menghasilkan gambaran dari perubahan garis pantai di Pantai Baron. Teknologi yang sering digunakan dalam pemantauan perubahan garis pantai adalah dengan menggunakan teknologi penginderaan jauh melalui perekaman citra satelit.

Penginderaan jauh meruapakn ilmu dan keterampilan yang digunakan oleh seseorang atau sekelompok orang untuk mengamati suatu benda atau objek sehingga dapat memperoleh informasi sesuai yang diinginkan tanpa harus bersentuhan secara langsung dengan benda atau objek yang akan diteliti (Halim et al, 2016). Keunggulan dari metode ini dibandingkan metode lainnya yaitu dapat mengambarkan obyek daerah dan gejala permukaan bumi dengan wujud dan letak obyek yang mirip dengan wujud di bumi.

\section{HASIL DAN PEMBAHASAN \\ Penentuan Ukuran dan Jensi Partikel Sedimen}

Penentuan ukuran dan jenis partikel sedimen diperoleh dengan melakukkan uji pada sampel sedimen dengan menggunakan alat Sieve Shaker di laboratorium. Hasil uji sampel sedimen ditampilkan pada Tabel 9. Berdasarkan pengolahan sampel sedimen Pantai Baron di laboraturium dan penghitungan statistik sedimen didapatkan hasil untuk ukuran butir dan jenis partikel sedimen antara stasiun 1, stasiun 2 dan stasiun 3 dengan mencocokan pada tabel Wentworth. Berikut hasil perhitungan statistik butir sedimen tiap stasiun yang telah dicocokan dengan Tabel Wentworth. Presentase sampel sedimen Pantai Baron yang lolos ayakan pada stasiun 1,2 dan 3 didominasi oleh pasir sedang, berikut Tabel 1.

Berdasarkan hasil pengolahan data sampel dari tiga titik pengambilan sampel, maka diperoleh jenis sedimen menunjukkan bahwa sampel didominasi jenis pasir berukuran sedang. Hal tersebut erat kaitannya dengan sumber sedimen dan karakteristik pantai. Material dari jenis pasir sedang berasal dari penghancuran batuan secara alami dalam jangka waktu yang panjang. Selain dari proses pelapukan batuan di daratan, sedimen yang terdapat pada perairan perairan Pantai Baron juga berasal dari pelapukan batuan yang terbawa aliran sungai.

Tabel 1. Presentase Berat Fraksi Sedimen Pasir

\begin{tabular}{|c|c|c|c|c|}
\hline No. & $\begin{array}{l}\text { Diameter } \\
(\mathrm{mm})\end{array}$ & $\begin{array}{l}\text { Berat } \quad \text { Fraksi } \\
\text { sedimen (gram) }\end{array}$ & $\begin{array}{lr}\text { Persen } & \text { berat } \\
\text { fraksi } & \text { sedimen } \\
(\%) & \end{array}$ & Klasifikasi \\
\hline 1. & 2 & 0 & 0 & - \\
\hline 2. & 0,5 & 5,15 & 5,18 & Pasir Sedang \\
\hline 3. & 0,3 & 25,83 & 26,06 & Pasir Sedang \\
\hline 4. & 0,15 & 53,32 & 53,88 & Pasir Sedang \\
\hline 5. & 0,063 & 10,2 & 10,39 & Pasir Halus \\
\hline 6. & $<0,063$ & 4,53 & 4,64 & Pasir Halus \\
\hline \multicolumn{2}{|c|}{ Total Sampel } & 99,03 & & \\
\hline
\end{tabular}

Karakteristik pantai juga sebagai salah satu faktor penentuan jenis sedimen. Pantai baron merupakan salah satu pantai yang memiliki aliran sungai bawah tanah, sehingga banyak partikel sedimen yang berasal dari sungai terbawa arus menuju laut. Ukuran butiran yang mendominasi pantai Baron memiliki diameter berkisar antara 0,0063-0,5 mm. 


\section{Kemiringan Pantai}

Hasil dari pengukuran dan pengolahan data kemiringan pantai di sajikan dalam bentuk tambel. Hasil yang diperoleh menunujukan bahwa kemiringan lereng Pantai Baron bervariasi. Dimana kemiringan pada transek 1 menunjukkan kondisi yang agak curam dengan presentase $14 \%$. Perbedaan pada transek 2 dan 3 memiliki klasifikasi yang landai dengan derajat diantara $4^{\circ}-8^{\circ}$. Perbedaan yang terjadi sangat terkait dengan kondisi topografi kawasan pantai dan variasi tekanan akibat gelombang dan pasang surut yang di terima sepanjang kawasan pantai serta karakter sedimen sebagai penyusun masa daratan. Menurut Kalay (2008) dinamika faktor hidro-oseanografi dan karakter massa daratan sangat mempengaruhi kestabilan lereng pantai mengindikasikan areal dekat pantai dan terjadinya abrasi di sepanjang pantai, berikut hasil data kemiringan pantai disajikan dalam Tabel 2.

Tabel 2. Hasil Data Kemiringan Pantai

\begin{tabular}{llll}
\hline $\begin{array}{l}\text { Transek } \\
\text { Pengamatan }\end{array}$ & $\begin{array}{l}\text { Sudut } \\
\text { kemiringan } \\
\text { lereng }\left({ }^{\circ}\right)\end{array}$ & $\begin{array}{l}\text { Presentase } \\
\text { kemiringan } \\
\text { lereng }(\%)\end{array}$ & Klasifikasi \\
\hline A.1 & 8 & 14 & $\begin{array}{l}\text { Agak } \\
\text { curam }\end{array}$ \\
A.2 & 9 & 15 & $\begin{array}{l}\text { Agak } \\
\text { curam }\end{array}$ \\
A.3 & 8,5 & 14,5 & $\begin{array}{l}\text { Agak } \\
\text { curam }\end{array}$ \\
B.1 & 3 & 5 & Landai \\
B.2 & 3 & 5,1 & Landai \\
B.3 & 3,5 & 5,4 & Landai \\
C1 & 6 & 7,6 & Landai \\
C2 & 6 & 7,5 & Landai \\
C3 & 6,1 & 7,7 & Landai \\
\hline
\end{tabular}

Sumber: Data lapangan 202

\section{Pola Angin Dan Peramalan Gelombang}

Berdasarkan hasil pengolahan data diperoleh nilai tinggi gelombang signifikan dan periode gelombang signifikan pada setiap musim, pada musim barat diperoleh hasil tinggi gelombang signifikan sebesar $0.803 \mathrm{~m}$, periode gelombang signifikan sebesar $3.545 \mathrm{~s}$.

Pada musim peralihan I tinggi gelombangnya $0.602 \mathrm{~m}$ dan periode gelombang $4.159 \mathrm{~s}$. Pada musim peralihan II memiliki nilai tinggi gelombang sebesar $0.685 \mathrm{~m}$ dan periode gelombang $4.428 \mathrm{~s}$, sedangkan pada musim timur memiliki nilai tinggi gelombang sebesar $0.743 \mathrm{~m}$ dengan periode $4.604 \mathrm{~s}$. Berikut Tabel 3 tinggi dan periode gelombang seperti Tabel 3.

Musim barat memiliki nilai tinggi gelombang signifikan tertinggi dibandingkan dengan musim Peralihan I, musim Timur, dan musim Peralihan II. Jika data tersebut dihubungkan dengan distribusi kecepatan angin dengan asumsi durasi dan fetch angin yang konstan, nilai tinggi gelombang memiliki hubungan yang linier dengan kecepatan angin (Smith dan Waseda, 2008). Hal ini berlaku pada musim Barat dimana memiliki distribusi frekuensi kecepatan angin tinggi (lebih dari 3,6 m/s) dibandingkan tiga musim lainnya yang menghasilkan tinggi gelombang signifikan tertinggi. 
Tabel 3. Tinggi dan Periode Gelombang

\begin{tabular}{lll}
\hline Musim & $\begin{array}{l}\text { Tinggi Signifikan }(\mathrm{Hs}) \\
(\mathrm{m})\end{array}$ & $\begin{array}{l}\text { Periode }(\mathrm{Ts}) \\
(\mathrm{s})\end{array}$ \\
\hline Musim Barat & 0,803 & 3,545 \\
Musim Peralihan I & 0,602 & 4,159 \\
Musim Timur & 0,685 & 4,428 \\
Peralihan II & 0,743 & 4,604 \\
\hline
\end{tabular}

Apabila diamati dari citra satelit google earth, arah datang gelombang sebagian besar dari arah barat daya dan tenggara. Pantai baron merupakan pantai yang berhadapan langsung dengan samudera hindia maka arah gelombang yang datang pasti dari arah selatan, namun akibat terhalang oleh perbukitan arah datang gelombang jadi terpisah menjadi dua arah yaitu barat daya dan tenggara. Arah datang gelombang ini juga mempengaruhi perubahan garis pantai, karena semakin besar energi gelombang menuju pantai berpasir secara tidak langsung mengakibatkan pergesekan antara gelombang dan dasar laut, sehingga terjadi gelombang pecah dan membentuk turbulensi yang kemudian membawa material disekitar pantai termasuk yang mengakibatkan pengikisan pada daerah sekitar pantai (erosi).

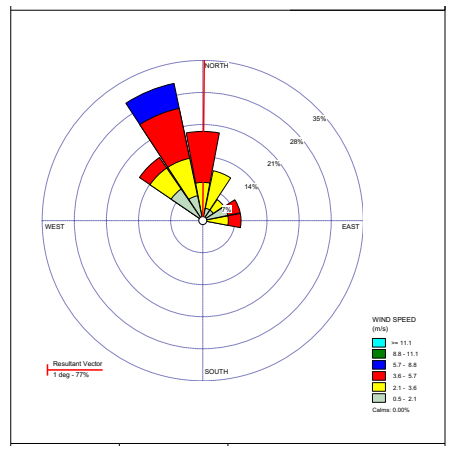

Gambar 1. Musim Barat arahTahun 2018 dari arah Barat Laut

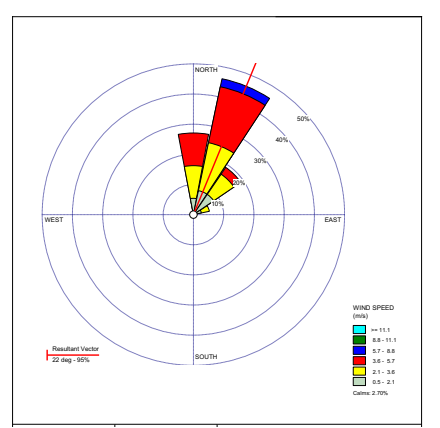

Gambar 3. Musim Timur Tahun 2018 dari arah Timur Laut

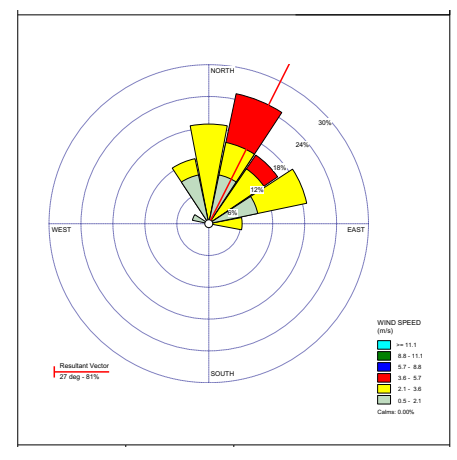

Gambar 2. Musim Peralihan I Tahun 2018 dari Timur Laut

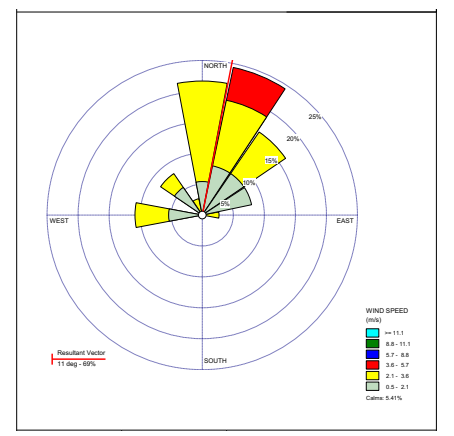

Gambar 4. Musim Peralihan II Tahun 2018 dari arah Timur Laut

Pada dasarnya proses perubahan pantai meliputi proses erosi dan akresi. Erosi pada sekitar pantai dapat terjadi apabila angkutan sedimen yang keluar ataupun yang pindah meninggalkan suatu daerah lebih besar dibandingkan dengan angkutan sedimen yang masuk, apabila terjadi sebaliknya maka yang terjadi adalah sedimentasi (Triatmodjo, 1991). 
Berdasarkan data penelitian, pada musim Peralihan I, musim Peralihan II dan musim Timur memiliki arah angin dominan yaitu Timur Laut dengan nilai kecepatan angin 3,6-5,7 m/s, namun pada musim Timur memiliki nilai kecepatan angin yang lebih tinggi yaitu sebesar 5,7 -8,8 $\mathrm{m} / \mathrm{s}$. Diatribusi kecepatan angin pada musim Barat memiliki arah dominan yaitu Barat Laut dengan nilai kecepatan angin berkisar antara 5,7-8,8 m/s dengan frekuensi $35 \%$.

\section{Pasang Surut}

Pengolahan data pasang surut di Pantai Baron dengan menggunakan metode admiralty sehingga diperoleh hasil komponen pasang surut. Data pasang surut yang digunakan diperoleh dari Badan Informasi Geospasial pada tahun 2018. Berikut hasil pasang surut disajikan dalam Tabel 4.

Tabel 4. Pasang Surut

\begin{tabular}{lllll}
\hline & $\begin{array}{l}\text { Nilai } \\
\text { Formzahl }\end{array}$ & $\begin{array}{l}\text { HHWL } \\
(\mathrm{cm})\end{array}$ & LLWL(cm) & MSL (cm) \\
\hline Musim Barat & 4,32 & 112,9 & 0,00 & 39,39 \\
Musim Peralihan I & 4,46 & 106 & 0,00 & 39,56 \\
Musim Timur & 4,56 & 112,6 & 0,00 & 38,43 \\
Musim Peralihan II & 4,67 & 107,86 & 0,00 & 39,11 \\
\hline
\end{tabular}

\section{Perubahan garis pantai}

Pantai Baron memiliki sifat yang cukup dinamis hal ini disebabkan karena adanya abrasi dan akresi. Abrasi terjadi karena adanya pengikisan pantai oleh hantaman gelombang laut yang menyebabkan berkurangnya areal daratan, sedangkan akresi merupakan perubahan garis pantai menuju laut lepas karena adanya proses sedimentasi dari daratan atau sungai menuju arah laut. Perubahan garis pantai dapat dilihat dari hasil tumpang susun (overlay). Overlay dilakukkan dengan menggabungkan hasil digitasi pada tahun 2010 dengan 2013, hasil digitasi 2013 dengan hasil digitasi 2016, hasil digitasi 2016 dengan hasil digitasi 2018. Rentang waktu antar penggabungan ini adalah 3 tahun dan 2 tahun, pengambilan waktu analisis perubahan garis pantai adalah 8 tahun (2010-2018).

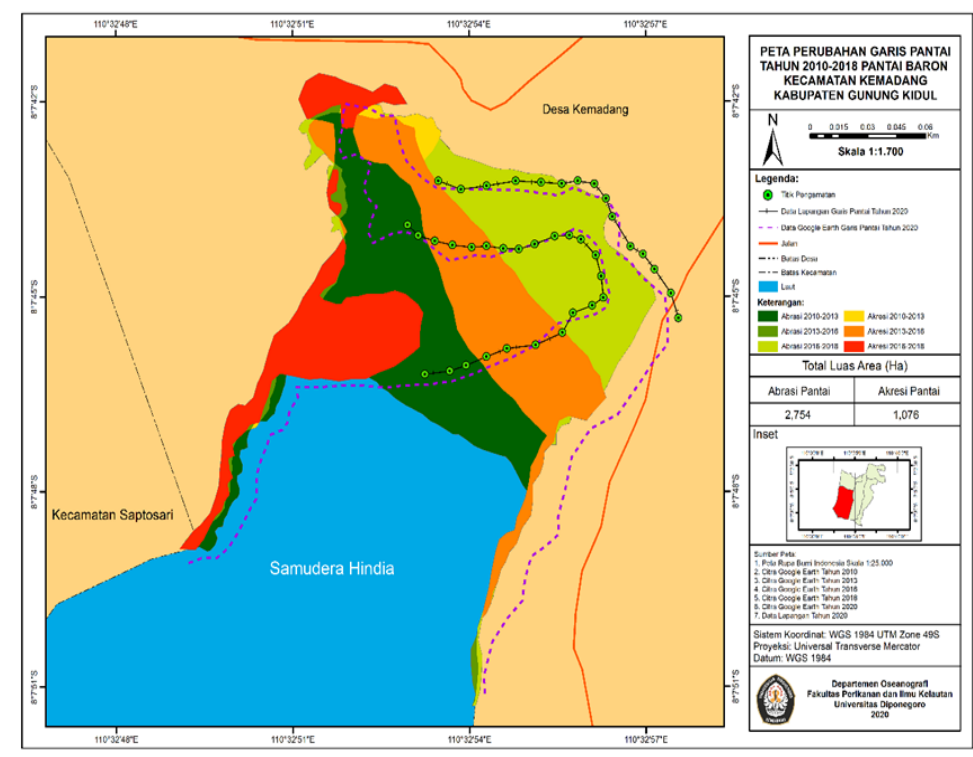

Gambar 5. Peta Perubahan Garis Pantai Tahun 2010-2018 
Tabel 5 menunjukan bahwa pada tahun 2010-2013 akresi yang terjadi sebesar 0,03ha dan abrasi 1,34 ha. Tahun 2013-2016 akresi yang terjadi 0,60 ha dan abrasi 0,23 ha. Tahun 2016-2018 akresi yang terjadi 0,43 ha dan abrasi 1,17 ha. Total luasan akresi pada tahun 2010-2018 yaitu 1,07 ha dan abrasi 2,75 ha. Nilai abrasi dan akresi ini juga dipengaruhi oleh muara sungai yang berada di pantai Baron, dimana sungai dapat mengakut partikel sedimen yang dapat menyebabkan perpindahan sedimen dari sungai menuju bibir pantai ataupun langsung menuju laut.

Tabel 5. Perubahan akresi atau abrasi garis pantai

\begin{tabular}{|c|c|c|c|c|}
\hline \multirow{2}{*}{$\begin{array}{l}\text { Penambahan/ } \\
\text { Pengurangan }\end{array}$} & \multicolumn{3}{|c|}{ Tahun } & \multirow{2}{*}{$\begin{array}{l}\text { Total Luasan } \\
\text { Akresi/ Abrasi } \\
\text { (ha) }\end{array}$} \\
\hline & $\begin{array}{l}2010- \\
2013\end{array}$ & $\begin{array}{l}2013- \\
2016\end{array}$ & $\begin{array}{c}2016- \\
2018\end{array}$ & \\
\hline Akresi & 0,03 & 0,60 & 0,43 & 1,07 \\
\hline Abrasi & 1,34 & 0,23 & 1,17 & 2,75 \\
\hline
\end{tabular}

\section{KESIMPULAN}

Luas perubahan garis pantai berdasarkan hasil interpretasi citra satelit google earth tahun 20102018, pada tahun 2010-2013 akresi yang terjadi sebesar 0,03 ha dan abrasi 1,34 ha. Tahun 2013-2016 akresi yang terjadi 0,60 ha dan abrasi 0,23 ha. Sedangkan tahun 2016-2018 akresi yang terjadi 0,43 ha dan abrasi 1,17 ha. Total luasan akresi pada tahun 2010-2018 yaitu 1,07 ha dan abrasi 2,75 ha.

Pantai Baron mengalami perubahan bentuk garis pantai yang cukup dinamis. Adanya perubahan garis pantai ini diduga disebabkan oleh perbedaan karakteristik pantai (faktor alam), antara lain faktor gelombang, pasang surut, dan angin.

\section{DAFTAR PUSTAKA}

Aguilar, F.J I, Fernandez J.L, Perez; A., Lopez M.A, Aguilar A., Mozas J., Cardenal, 2010. Preliminary Results on High Accuracy Estimation of Shoreline Change Rate Based on Coastal Elevation Models. International Archives of the Photogrammetry, Remote Sensing and Spatial Information Science, International Archives of the Photogrammetry, Remote Sensing and Spatial Information Science, 38(8): 986-991

Anisa Hapsari Kusumastuti dan Adjie Pamungkas. 2018. Identifikasi Potensi dan Permasalahan Daya Dukung Lingkungan berdasarkan Aspek Daya Dukung Fisik, Daya Dukung Ekologis dan Daya Dukung Sosial pada Pantai Baron Kabupaten Gunungkidul Yogyakarta. Jurnal Teknik ITS, 7(1):2337-3520

Degen E. Kalay, Villian F. Lopulissa dan Yunita A. Noya. 2018. Analisis Kemiringan Lereng Pantai Dan Distribusi Sedimen Pantai Perairan Negeri Waai Kecamatan Salahutu Provinsi Maluku. Jurnal Triton, 14(1), hal 10-18

Halim, Halili, La Ode Alirman Afu. 2016. Studi Perubahan Garis Pantai Dengan Pendekatan Penginderaan Jauh Di Wilayah Pesisir Kecamatab Soropia. Sapa Laut, E-ISSN, 1(1): 24-31

Muhammad Zainuddin Lubis, Hanah Khoirunnisa. 2013. Dinamika Pantai Praikalogu Di Provinsi Nusa Tenggara Barat, Indonesia. P-ISSN, 8(2) : 2085-3835

Sugiyono, 2009, Metode Penelitian Kuantitatif, Kualitatif dan R\&D, Bandung: Alfabeta.

Triatmodjo, Bambang. 1999. Teknik Pantai.Beta Offset, Yogyakarta, 367 hlm. 